\title{
Inequalities in participation and time spent in moderate-to-vigorous physical activity: a pooled analysis of the cross-sectional health surveys for England 2008, 2012, and 2016
}

Shaun Scholes ${ }^{*}$ and Jennifer S. Mindell

\begin{abstract}
Background: Evidence is unclear on whether inequalities in average levels of moderate-to-vigorous physical activity (MVPA) reflect differences in participation, differences in the amount of time spent active, or both. Using self-reported data from 24,882 adults (Health Survey for England 2008, 2012, 2016), we examined gender-specific inequalities in these separate aspects for total and domain-specific MVPA.

Methods: Hurdle models accommodate continuous data with excess zeros and positive skewness. Such models were used to assess differences between income groups in three aspects: (1) the probability of doing any MVPA, (2) the average hours/week spent in MVPA, and (3) the average hours/week spent in MVPA conditional on participation (MVPA-active). Inequalities were summarised on the absolute scale using average marginal effects (AMEs) after confounder adjustment.

Results: Inequalities were robust to adjustment in each aspect for total MVPA and for sports/exercise. Differences between adults in high-income versus low-income households in sports/exercise MVPA were $2.2 \mathrm{~h} /$ week among men (95\% confidence interval $(\mathrm{Cl}): 1.6,2.8)$ and $1.7 \mathrm{~h} /$ week among women $(95 \% \mathrm{Cl}: 1.3,2.1)$; differences in sports/exercise MVPA-active were $1.3 \mathrm{~h} /$ week $(95 \% \mathrm{Cl}: 0.4,2.1)$ and $1.0 \mathrm{~h} /$ week $(95 \% \mathrm{Cl}: 0.5,1.6)$ for men and women, respectively. Heterogeneity in associations was evident for the other domains. For example, adults in high-income versus lowincome households were more likely to do any walking (men: 13.0\% (95\% Cl: 10.3, 15.8\%); women: 10.2\% (95\% Cl: 7.6, 12.8\%)). Among all adults (including those who did no walking), the average hours/week spent walking showed no difference by income. Among those who did any walking, adults in high-income versus low-income households walked on average $1 \mathrm{~h} /$ week less (men: $-0.9 \mathrm{~h} /$ week (95\% Cl: - 1.7, - 0.2); women: $-1.0 \mathrm{~h} /$ week (95\% Cl: - 1.7, - 0.2)).

*Correspondence: s.scholes@ucl.ac.uk

Research Department of Epidemiology and Public Health, University College

London, 1-19 Torrington Place, London WC1E 7HB, UK

(c) The Author(s). 2020 Open Access This article is licensed under a Creative Commons Attribution 4.0 International License, which permits use, sharing, adaptation, distribution and reproduction in any medium or format, as long as you give appropriate credit to the original author(s) and the source, provide a link to the Creative Commons licence, and indicate if changes were made. The images or other third party material in this article are included in the article's Creative Commons licence, unless indicated otherwise in a credit line to the material. If material is not included in the article's Creative Commons licence and your intended use is not permitted by statutory regulation or exceeds the permitted use, you will need to obtain permission directly from the copyright holder. To view a copy of this licence, visit http://creativecommons.org/licenses/by/4.0/. The Creative Commons Public Domain Dedication waiver (http://creativecommons.org/publicdomain/zero/1.0/) applies to the data made available in this article, unless otherwise stated in a credit line to the data. 
(Continued from previous page)

Conclusions: Participation and the amount of time that adults spend in MVPA typically favours those in high-income households. Monitoring inequalities in MVPA requires assessing different aspects of the distribution within each domain. Reducing inequalities in sports/exercise requires policy actions and interventions to move adults in lowincome households from inactivity to activity, and to enable those already active to do more. Measures to promote walking should focus efforts on reducing the sizeable income gap in the propensity to do any walking.

Keywords: Physical activity, Moderate-to-vigorous intensity physical activity, Inequalities, Hurdle models

\section{Background}

Being physically active increases cardiometabolic health and reduces risk of cardiovascular-related morbidity and mortality [1]. Inequalities in physical activity (PA) contribute to social gradients in health $[2,3]$. However, previous studies on inequalities in adult PA have produced inconsistent findings due, at least in part, to heterogeneity in analysis techniques such as choice of PA indicator and whether assessment was made for total or domain-specific PA $[4,5]$.

The direction and/or magnitude of inequalities can also vary by whether PA is analysed as a binary, ordinal or continuous variable. Whilst enabling assessment with regard to PA recommendations, categorising a continuous variable such as the hours-per-week spent in moderate-to-vigorous PA (MVPA) into a binary $[4,6]$ or ordinal variable $[7,8]$ loses extensive information in the discretisation and is suboptimal both in terms of power and bias [9]. Yet analysing the continuous variable is also problematic. First, analyses based on the mean can mask inequalities in other parts of the distribution (e.g. at the lower- or upper-tails) [10]. Quantile regression facilitates assessment across continuous distributions; evidence suggests larger inequalities at the upper-tail of the body mass index (BMI) distribution [11, 12]. Secondly, MVPA distributions are not typically normally distributed but are characterised by excess zeros (persons not doing any) and positive skewness (high MVPA for a small number of highly active adults) [13], with each aspect potentially having different determinants [14].

Hurdle models such as those proposed by Cragg [15] can handle continuous MVPA data with excess zeros and positive skewness [13] as they treat participation and the amount of time spent active (conditional on participation) separately. Although used in the economics literature, especially for sports participation $[14,16]$, no epidemiological studies to date have used hurdle models to quantify inequalities in MVPA, despite the potential advantages for policy-makers and practitioners. Such advantages stem from simultaneously fitting separate model equations for participation (i.e. whether persons engage in MVPA or not) and for duration (i.e. the amount of time persons who do participate spend being active). By making this distinction, the results from hurdle models allow policymakers and practitioners to evaluate whether factors such as income influence MVPA in the same or in opposite directions (e.g. higher income groups having higher participation rates but, conditional on participating, spending less time engaged) [14]. Such a distinction - suggesting policy actions and interventions be focused on increasing participation rather than increasing PA duration among those who are already active - is not possible using single equation models. Using nationally-representative health survey data, we applied hurdle models to quantify inequalities in total and domain-specific MVPA. We hypothesised that adults in high-income versus low-income households are more likely to participate in MVPA, and that conditional on doing any MVPA, spend more time on average being active.

\section{Methods}

\section{Study sample}

Data came from the Health Survey for England (HSE): this dataset is used to monitor progress on numerous national health objectives, including PA $[17,18]$. Details about the HSE sample design and data collection are described elsewhere [19]. Briefly, the HSE annually draws a nationallyrepresentative sample of people living in private households in England using multistage stratified probability sampling with postcode sectors as the primary sampling unit and the Postcode Address File as the household sampling frame. All adults in selected households are eligible for interview. Fieldwork takes place continuously through the year. Trained interviewers measured participants' height and weight and assessed their demographic characteristics, selfreported health, and health behaviours including PA using computer-assisted personal interviewing. We used the most recent surveys $(2008,2012,2016)$ that included the adult Physical Activity and Sedentary Behaviour Assessment Questionnaire (PASBAQ).

The household response rate ranged from $64 \%$ in 2008 to $59 \%$ in 2016 . This study is restricted to adults (i.e. aged 16 years or over). Participants gave verbal consent for interview. Relevant committees granted research ethics approval for the survey. Overall, 31,399 adults participated in the three surveys, of whom 31,183 had valid PA data. Of these, 6301 had missing income data, leaving an analytical sample of 24,882 adults with complete data. 


\section{Assessment of leisure-time physical activity}

PASBAQ data is used to monitor adherence to UK PA recommendations $[17,18]$ and for other epidemiological research $[20,21]$. The PASBAQ has demonstrated moderate-weak convergent validity in comparison with non-synchronous accelerometry [22]. PASBAQ assesses frequency (number of days in the last 4 weeks) and duration (of an average episode of at least $10 \mathrm{~min}$ ) in four leisure-time domains [23]:

- "light" and "heavy" domestic activity;

- "light" and "heavy" manual work (e.g. 'Do-ItYourself (DIY));

- walking (with no distinction between walking for leisure or travel); and

- sports/exercise (ten specific and six 'other' activities).

"Heavy" domestic and manual activities were classed as moderately-intensive. Walking intensity was assessed by a question on usual walking-pace (responses: slow, average, fairly brisk, or fast); moderate-intensity was classed as a fairly brisk or fast pace. Intensity of sports/ exercise was determined as indexed in the metabolic equivalent (METs) compendium [24, 25] and a followup question on whether the activity had made the participant "out-of-breath or sweaty".

\section{Assessment of occupational physical activity}

In addition to leisure-time PA, participants engaged in any paid or unpaid work answer questions on occupational PA. Our analyses classed three activities - walking, climbing stairs or ladders, and lifting, carrying, or moving heavy loads - as moderate-intensity PA for participants working in occupations identified a-priori as moderately-intensive [17].

\section{Assessment of time spent in MVPA}

Time spent in domain-specific MVPA was calculated as the product of frequency and duration, converted from the last 4 weeks to hours/week. For sports/exercise, time in vigorous-intensity activities was multiplied by two when combined with moderate-intensity activities to calculate 'equivalent' hours/week as specified in MVPA guidelines [26]. Total MVPA was calculated by summing across the five domains (four leisure-time plus occupational), and was truncated at a maximum of $40 \mathrm{~h} /$ week to minimise unrealistic values.

\section{Socioeconomic position ascertainment and confounders}

Household income was our chosen marker of socioeconomic position (SEP). The household reference person reports annual gross household income via a showcard (31 bands ranging from 'less than $£ 520$ ' to ' $£ 150,000+$ '). Household income is equivalised (McClements scale
[27]), and grouped into tertiles. Age (in ten-year bands), current smoking (current, ex-regular, never), self-rated health ('very good/good', 'fair', or 'bad/very bad'), and BMI were chosen as potential confounders of the SEP and MVPA associations [6]. We computed BMI as weight in kilogrammes $(\mathrm{kg})$ divided by height in metres squared $\left(\mathrm{m}^{2}\right)$, classifying participants into four groups according to the World Health Organization (WHO) BMI classification [28]: underweight $\left(<18.5 \mathrm{~kg} / \mathrm{m}^{2}\right)$, normal-weight $\left(18.5-24.9 \mathrm{~kg} / \mathrm{m}^{2}\right)$, overweight $(25.0-$ $29.9 \mathrm{~kg} / \mathrm{m}^{2}$ ), or obese (at least $30.0 \mathrm{~kg} / \mathrm{m}^{2}$ ).

\section{Statistical analysis \\ Descriptive estimates}

Data was pooled over the three surveys to increase precision (prior analyses revealed no change in associations over time). Differences in age, self-rated health, current smoking, and BMI were estimated by income, using Rao-Scott tests for independence [29]. For total and domain-specific MVPA, we computed descriptive estimates for four outcomes:

- \% doing any;

- \% 'sufficiently' active (i.e. at least $2.5 \mathrm{~h} /$ week MVPA [26]);

- average hours/week MVPA (range: 0 to $40 \mathrm{~h} /$ week); and

- average hours/week MVPA among those doing any (range: 0.042 to $40 \mathrm{~h} /$ week; hereafter referred to as MVPA-active).

Outcomes MVPA and MVPA-active represent unconditional and conditional (on participation) means, respectively. We decided, a-priori, to conduct genderstratified analyses due to expected differences in inequalities as reported in the literature [7, 8, 30]. Incomespecific estimates were directly age-standardised within gender using the pooled data as standard. Pairwise differences between income groups (low-income households as reference) were evaluated on the absolute scale using a linear combination of the coefficients [31].

\section{Hurdle models}

To handle continuous MVPA data with excess zeros and positive skewness, we used the hurdle model proposed by Cragg, which comprises two parts: a selection/participation model and a latent model [15]. The former determines the boundary points of the continuous outcome (a selection variable equals 1 if not bounded and 0 otherwise), whilst the latter determines its unbounded values (a continuous latent variable which is observed only if the selection variable equals 1). In our analyses, the selection model assessed the influence of income on the binary outcome of 
participation (any versus none), whilst the latent model assessed its influence on the amount of time spent active, conditional on participation (MVPA-active). We specified a probit model for the former and an exponential form for the latter. Each model contained income (as a three-category variable) and the confounders listed above.

Based on the model estimates, three sets of marginal means by income were calculated, evaluated at fixed values of the confounders. These sets correspond to different definitions of the expected value of MVPA [32]: (i) the probability of doing any, (ii) the average hours/week MVPA for all participants (the unconditional mean), including those who did none; and (iii) the average hours/week MVPA conditional on participation (MVPA-active). Inequalities after confounder adjustment (average marginal effects: AMEs) were quantified by computing the absolute difference in the marginal means (low-income as reference).

Dataset preparation and analysis was performed in SPSS V20.0 (SPSS IBM Inc., Chicago, Illinois, USA) and Stata V15.0 (College Station, Texas, USA), respectively. All analyses accounted for the complex survey design by applying sample weights (including correction for nonresponse) and incorporating the clustering of participants in postcode sectors (the primary sampling unit in the HSE series) via the "svy" package in Stata. HSE datasets are available via the UK Data Service (http://www. ukdataservice.ac.uk) [33-35]; statistical code is available from the corresponding author.

\section{Results}

\section{Characteristics by income}

Information on confounders by income is presented in Additional file 1 . Poorer self-rated health and higher smoking levels were evident among adults in lowincome households (both $P<0.001$ ). BMI status also varied by income ( $\mathrm{P}<0.001$ for both genders), with higher obesity levels especially among women in low-income households (Additional file 1).

\section{Descriptive estimates}

Tables 1 and 2 show the descriptive estimates for total and domain-specific MVPA for all adults and by income for men and women, respectively. Overall, $85 \%$ of men $(n=9254)$ and $81 \%$ of women $(n=10,947)$ did any MVPA; $66 \%$ of men $(n=7120)$ and $56 \%$ of women $(n=$ 7537) were 'sufficiently' active (Table 1 men; Table 2 women). Men and women spent on average 9.7 and 6.8 $\mathrm{h}$ /week respectively in total MVPA (Table 1 men; Table 2 women); however, these distributions showed excessive zeros and positive skewness (Fig. 1). Among those doing any MVPA, men and women spent on average 11.5 and $8.4 \mathrm{~h} /$ week respectively in total MVPA (Table $1 \mathrm{men}$;
Table 2 women). The largest difference between MVPA and MVPA-active means was for occupational PA; among men, these were 2.5 and $15.2 \mathrm{~h}$ /week respectively (Table 1 men; Table 2 women).

Inequalities were evident in descriptive analyses in each aspect for total MVPA and for sports/exercise. Differences between high-income versus low-income households in total MVPA were $2.2 \mathrm{~h} /$ week among men $(95 \% \mathrm{CI}: 1.7$, 2.8; $P<0.001)$ and $1.8 \mathrm{~h} /$ week among women $(95 \% \mathrm{CI}: 1.3$, 2.2; $P<0.001$ ); the same pattern, but with narrower effect sizes, was found for total MVPA-active (men: $0.9 \mathrm{~h} /$ week, 95\% CI: 0.3, 1.6; $P=0.004$; women: $1.0 \mathrm{~h} /$ week, $95 \% \mathrm{CI}$ : $0.6,1.5 ; \mathrm{P}<0.001$ ) (Table 1 men; Table 2 women). Likewise, differences in sports/exercise MVPA (i.e. including those who did none) for men and women in high-income versus low-income households were $1.9 \mathrm{~h} /$ week $(95 \% \mathrm{CI}$ : 1.6, 2.2; $\mathrm{P}<0.001)$ and $1.5 \mathrm{~h} /$ week $(95 \% \mathrm{CI}: 1.3,1.7$; $\mathrm{P}<0.001$ ), respectively (Table 1 men; Table 2 women). Differences in sports/exercise MVPA-active were $1.2 \mathrm{~h}$ /week among men (95\% CI: 0.7, 1.7; $P<0.001)$ and $1.1 \mathrm{~h} /$ week (95\% CI: 0.7, 1.5; P < 0.001) among women (Table 1 men; Table 2 women).

Results for other domains were heterogeneous. Inequalities were evident in the unconditional outcomes (any; sufficient activity; MVPA) for walking, yet the time spent walking amongst those who did any walking was higher among men in low-income versus high-income households (levels were similar by income among women). Men in high-income versus low-income households did less occupational PA (MVPA: $P=0.021$; MVPA-active: $P=0.019$ ); whilst men (MVPA-active: $P<0.001)$ and women $(\mathrm{P}<0.001$ for MVPA and MVPA-active) in high-income households did less domestic activity (Table 1 men; Table 2 women).

\section{Multivariable hurdle models}

Table 3 shows the AMEs from estimated hurdle models corresponding to the absolute difference in the marginal means for the binary outome of participation, and the continuous outcomes of MVPA and MVPA-active (AMEs are graphically shown in Fig. 2).

Higher MVPA in high-income versus low-income households was robust to confounder adjustment for total MVPA and for sports/exercise $(\mathrm{P}<0.001$ for all outcomes and both genders; except $P=0.003$ for sports/exercise MVPA-active among men) (Table 3). For example, at fixed values of the confounding variables, differences between high-income versus low-income households in sports/exercise MVPA were $2.2 \mathrm{~h} /$ week among men (95\% CI: $1.6,2.8)$ and $1.7 \mathrm{~h} /$ week among women (95\% CI: 1.3 , 2.1); differences in sports/exercise MVPA-active were 1.3 h/week (95\% CI: 0.4, 2.1) and 1.0 h/week (95\% CI: 0.5, 1.6) for men and women, respectively (Table 3 ). 
Table 1 Total and domain-specific MVPA outcomes by income tertile among men, Health Survey for England 2008,2012 and 2016

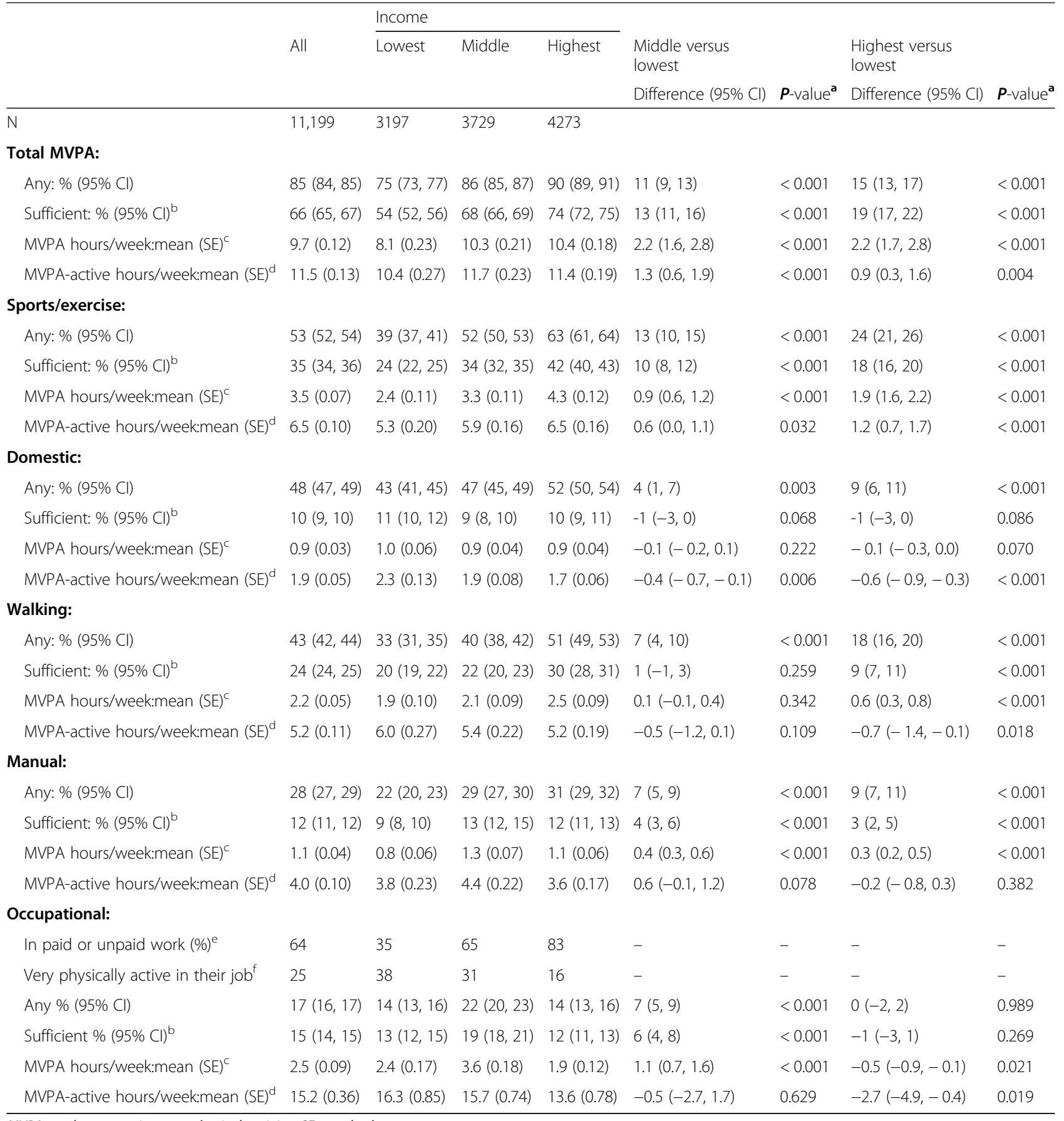

MVPA moderate-to-vigorous physical activity, SE standard error

${ }^{\mathrm{a} P} P$-values calculated via linear combination of coefficients

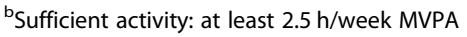

'MVPA hours/week includes all participants, including those inactive (range: 0 to $40 \mathrm{~h} /$ week)

${ }^{\mathrm{d}}$ MVPA-active hours/week restricted to active participants (range: 0.042 to $40 \mathrm{~h} /$ week)

EEstimates are unweighted

fParticipants doing any paid or unpaid work were asked how physically active they were in their job (responses: very; fairly; not very; not at all). Estimates are unweighted 
Table 2 Total and domain-specific MVPA by income tertile among women, Health Survey for England 2008, 2012 and 2016

\begin{tabular}{|c|c|c|c|c|c|c|c|c|}
\hline & \multirow[t]{2}{*}{ All } & \multirow[t]{2}{*}{ Lowest } & \multirow[t]{2}{*}{ Middle } & \multirow[t]{2}{*}{ Highest } & \multicolumn{2}{|l|}{$\begin{array}{l}\text { Middle versus } \\
\text { lowest }\end{array}$} & \multicolumn{2}{|l|}{$\begin{array}{l}\text { Highest versus } \\
\text { lowest }\end{array}$} \\
\hline & & & & & Difference (95\% Cl) & $\boldsymbol{P}$-value ${ }^{a}$ & Difference $(95 \% \mathrm{Cl})$ & $\boldsymbol{P}$-value ${ }^{a}$ \\
\hline N & 13,683 & 4605 & 4627 & 4451 & & & & \\
\hline \multicolumn{9}{|l|}{ Total MVPA: } \\
\hline Any: \% (95\% Cl) & $81(80,82)$ & $74(73,76)$ & $81(80,82)$ & $86(85,88)$ & $7(5,8)$ & $<0.001$ & $12(10,14)$ & $<0.001$ \\
\hline Sufficient: \% $\left(95 \%\right.$ Cl) ${ }^{b}$ & $56(55,57)$ & $49(47,50)$ & $56(54,57)$ & $63(62,65)$ & $7(5,9)$ & $<0.001$ & $14(12,16)$ & $<0.001$ \\
\hline MVPA hours/week:mean $(\mathrm{SE})^{\mathrm{c}}$ & $6.8(0.09)$ & $5.8(0.15)$ & $6.9(0.14)$ & $7.6(0.16)$ & $1.1(0.7,1.5)$ & $<0.001$ & $1.8(1.3,2.2)$ & $<0.001$ \\
\hline MVPA-active hours/week:mean (SE) ${ }^{d}$ & $8.4(0.10)$ & $7.6(0.17)$ & $8.3(0.16)$ & $8.6(0.17)$ & $0.7(0.3,1.2)$ & 0.001 & $1.0(0.6,1.5)$ & $<0.001$ \\
\hline \multicolumn{9}{|l|}{ Sports/exercise: } \\
\hline Any: \% (95\% Cl) & $44(43,45)$ & $32(30,33)$ & $43(41,44)$ & $55(54,57)$ & $11(9,13)$ & $<0.001$ & $24(22,26)$ & $<0.001$ \\
\hline Sufficient: \% $\left(95 \%\right.$ Cl) ${ }^{b}$ & $23(22,23)$ & $15(13,16)$ & $21(20,23)$ & $30(29,32)$ & $7(5,8)$ & $<0.001$ & $16(14,18)$ & $<0.001$ \\
\hline MVPA hours/week:mean (SE) ${ }^{c}$ & $2.0(0.04)$ & $1.3(0.06)$ & $1.8(0.06)$ & $2.8(0.09)$ & $0.5(0.4,0.7)$ & $<0.001$ & $1.5(1.3,1.7)$ & $<0.001$ \\
\hline MVPA-active hours/week:mean (SE) ${ }^{d}$ & $4.5(0.08)$ & $3.7(0.13)$ & $4.0(0.12)$ & $4.8(0.15)$ & $0.3(0.0,0.7)$ & 0.051 & $1.1(0.7,1.5)$ & $<0.001$ \\
\hline \multicolumn{9}{|l|}{ Domestic: } \\
\hline Any: \% (95\% Cl) & $61(60,62)$ & $60(59,62)$ & $61(60,63)$ & $60(59,62)$ & $1(-1,3)$ & 0.505 & $0(-2,2)$ & 0.915 \\
\hline Sufficient: \% $(95 \% \mathrm{Cl})^{\mathrm{b}}$ & $20(19,20)$ & $22(21,23)$ & $20(19,22)$ & $17(16,19)$ & $-2(-4,0)$ & 0.059 & $-5(-6,-3)$ & $<0.001$ \\
\hline MVPA hours/week:mean (SE) ${ }^{c}$ & $1.7(0.03)$ & $2.0(0.07)$ & $1.8(0.06)$ & $1.4(0.05)$ & $-0.2(-0.4,0.0)$ & 0.017 & $-0.6(-0.7,-0.4)$ & $<0.001$ \\
\hline MVPA-active hours/week:mean (SE) ${ }^{d}$ & $2.8(0.05)$ & $3.2(0.10)$ & $2.8(0.09)$ & $2.3(0.08)$ & $-0.3(-0.6,-0.1)$ & 0.013 & $-0.8(-1.0,-0.6)$ & $<0.001$ \\
\hline \multicolumn{9}{|l|}{ Walking: } \\
\hline Any: \% (95\% Cl) & $35(34,35)$ & $27(25,28)$ & $33(32,34)$ & $43(41,44)$ & $6(4,8)$ & $<0.001$ & $16(14,18)$ & $<0.001$ \\
\hline Sufficient: $\%(95 \% \text { Cl) })^{b}$ & $22(21,23)$ & $18(16,19)$ & $21(20,23)$ & $27(25,28)$ & $4(2,5)$ & $<0.001$ & $9(7,11)$ & $<0.001$ \\
\hline MVPA hours/week:mean (SE) ${ }^{c}$ & $1.9(0.05)$ & $1.5(0.07)$ & $1.8(0.07)$ & $2.3(0.09)$ & $0.4(0.2,0.5)$ & $<0.001$ & $0.8(0.6,1.1)$ & $<0.001$ \\
\hline MVPA-active hours/week:mean (SE) ${ }^{d}$ & $5.5(0.11)$ & $5.6(0.19)$ & $5.8(0.22)$ & $5.8(0.21)$ & $0.2(-0.4,0.7)$ & 0.526 & $0.2(-0.4,0.7)$ & 0.495 \\
\hline \multicolumn{9}{|l|}{ Manual: } \\
\hline Any: \% (95\% Cl) & $12(12,13)$ & $10(9,11)$ & $12(12,13)$ & $14(13,15)$ & $2(1,3)$ & 0.005 & $3(2,5)$ & $<0.001$ \\
\hline Sufficient: \% $\left(95 \%\right.$ Cl) ${ }^{b}$ & $4(4,4)$ & $3(3,4)$ & $4(4,5)$ & $4(4,5)$ & $1(0,2)$ & 0.003 & $1(0,2)$ & 0.009 \\
\hline MVPA hours/week:mean (SE) ${ }^{c}$ & $0.4(0.02)$ & $0.3(0.02)$ & $0.4(0.03)$ & $0.4(0.03)$ & $0.1(0.0,0.2)$ & 0.008 & $0.1(0.0,0.2)$ & 0.016 \\
\hline MVPA-active hours/week:mean (SE) ${ }^{d}$ & $2.9(0.11)$ & $2.7(0.19)$ & $3.1(0.23)$ & $2.5(0.16)$ & $0.4(-0.2,1.0)$ & 0.177 & $-0.2(-0.7,0.3)$ & 0.408 \\
\hline \multicolumn{9}{|l|}{ Occupational: } \\
\hline In paid or unpaid work (\%) & 55 & 32 & 57 & 75 & - & - & - & - \\
\hline Very physically active in their job $b^{f}$ & 19 & 29 & 22 & 12 & - & - & - & - \\
\hline Any: \% (95\% Cl) & $7(7,7)$ & $7(6,7)$ & $9(8,9)$ & $6(6,7)$ & $2(1,3)$ & 0.002 & $0(-1,1)$ & 0.678 \\
\hline Sufficient: \% $\left(95 \%\right.$ Cl) ${ }^{b}$ & $6(6,6)$ & $6(5,6)$ & $8(7,8)$ & $5(5,6)$ & $2(1,3)$ & $<0.001$ & $0(-1,1)$ & 0.658 \\
\hline MVPA hours/week:mean (SE) ${ }^{c}$ & $1.0(0.04)$ & $0.9(0.08)$ & $1.3(0.08)$ & $0.8(0.07)$ & $0.4(0.1,0.6)$ & 0.001 & $-0.1(-0.3,0.1)$ & 0.329 \\
\hline MVPA-active hours/week:mean (SE) ${ }^{d}$ & $14.2(0.39)$ & $12.7(0.66)$ & $14.6(0.65)$ & $12.7(0.59)$ & $1.9(0.1,3.7)$ & 0.043 & $-0.1(-1.9,1.7)$ & 0.930 \\
\hline
\end{tabular}

MVPA moderate-to-vigorous physical activity, SE standard error

${ }^{\mathrm{a}} P$-values calculated via linear combination of coefficients

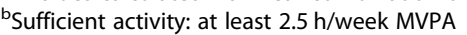

'MVPA hours/week includes all participants, including those inactive (range: 0 to $40 \mathrm{~h} /$ week)

${ }^{\mathrm{d}}$ MVPA-active hours/week restricted to active participants (range: 0.042 to $40 \mathrm{~h} /$ week)

${ }^{e}$ Estimates are unweighted

'Participants doing any paid or unpaid work were asked how physically active they were in their job (responses: very; fairly; not very; not at all). Estimates are unweighted

Heterogeneity in associations was observed for other domains. Participants in high-income versus low-income households were more likely to do any walking (men: $13.0 \%$ (95\% CI: 10.3, 15.8\%); women: $10.2 \%$ (95\% CI: 7.6, 12.8\%)). Among all adults (including those who did no walking), the average hours/week spent walking showed no difference by income. Among those who did any walking, adults in highincome versus low-income households walked on average $1 \mathrm{~h} /$ week less (men: $-0.9 \mathrm{~h} /$ week $(95 \% \mathrm{CI}:-1.7,-0.2)$; women: $-1.0 \mathrm{~h} /$ week $(95 \% \mathrm{CI}:-1.7,-0.2)$ ) (Table 3$)$. 


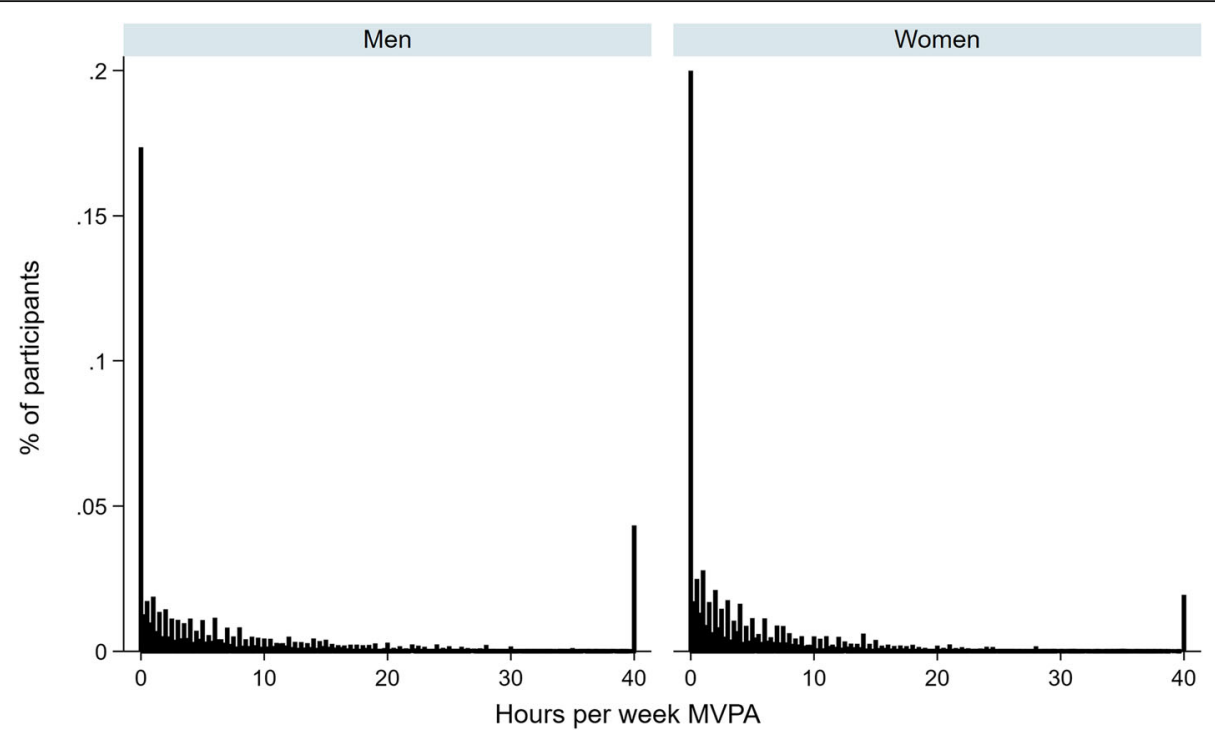

Fig. 1 Distribution of hours per week spent in total MVPA by gender

Women in high-income versus low-income households were less likely to do any $(-4.0 \%$; $95 \% \mathrm{CI}:-6.0$, $-1.9 \%, P<0.001)$ and spent less time in domestic activity ( $\mathrm{P}<0.001$ for MVPA and MVPA-active) (Table 3). Lower levels of occupational PA for men in high-income versus low-income households were robust to confounder adjustment $(P=0.001$ and $\mathrm{P}<0.001$ for MVPA and MVPAactive) (Table 3$)$.

\section{Discussion}

Applying hurdle models to investigate inequalities in total and domain-specific MVPA, we hypothesised that adults in high-income households were more likely both to participate in MVPA than adults in low-income households and, conditional on doing any, to spend more time on average being active. These hypotheses were confirmed in fully-adjusted analyses for total MVPA and for sports/exercise. For example, among those doing any sports/exercise, men and women in high-income households spent on average 1.3 and 1.0 more hours/week in sports/exercise respectively, than their counterparts in low-income households (Table 3). Results for the other domains were mixed. Adults in high-income versus low-income households were more likely to do any walking. Among all adults (including those who did no walking), the average hours/week spent walking showed no difference by income. Among those who did any walking, adults in highincome versus low-income households walked on average $1 \mathrm{~h} /$ week less.

Comparisons with previous studies are difficult due to differences in study characteristics and analytical strategy. Bearing this caveat in mind, the inequalities in
MVPA presented here agree with recent analyses of HSE data $[7,8]$, and with other European-wide [30, 36] and US $[4,6]$ studies. Our results showing that inequalities differ by domain corroborate both systematic reviews [5] and previous empirical studies [4], reflecting differences across SEP in how MVPA is accrued. In agreement with other reports [8], we found that inequalities in total MVPA were driven in the main by sports/exercise, which contributes a larger proportion of total MVPA for adults, especially men, in high-income households. This result also reflects inequalities in vigorous-intensity sports/exercise (data not shown), which is given twice the weight of moderate-intensity activities in our analyses in accordance with guidelines [26]. Inequalities in total and sports/exercise MVPA were partially offset by the reverse pattern for occupational PA, consistent with previous studies [4], reflecting the higher involvement of lower SEP groups in physically demanding work. Whilst occupational PA is taken into account in monitoring adherence to MVPA guidelines using HSE data [17, 18], high levels of strenuous occupational PA can be detrimental for health [37, 38].

Our findings add to the literature by assessing whether inequalities exist in the propensity to be active, in the amount of time spent active, or in both. Practitioners using the (unconditional) average to summarise inequalities should perform additional analyses to decompose this into its two parts: i.e. the probability of participation and the (conditional) average among those doing any [32]. Such decomposition can potentially shed light on the inequality determinants in the lower-tail of the distribution (drivers of inactivity) and those impacting the positive, non-zero, part of the distribution, implying potentially different tailored policy actions and 
Table 3 Parameter estimates from multivariable hurdle models (any participation and amount of time spent active), Health Survey for England 2008, 2012 and 2016

\begin{tabular}{|c|c|c|c|c|c|c|}
\hline \multirow{2}{*}{$\begin{array}{r}. \\
\end{array}$} & \multirow{2}{*}{$\begin{array}{l}\text { Any (\%) } \\
\text { AME }(95 \% \mathrm{Cl})^{\mathrm{a}}\end{array}$} & \multirow[t]{2}{*}{$\boldsymbol{P}$-value } & $\begin{array}{l}\text { Unconditional: Mean } \\
\text { MVPA hours/week }\end{array}$ & \multirow[t]{2}{*}{$\boldsymbol{P}$-value } & \multirow{2}{*}{$\begin{array}{l}\text { Conditional: Mean } \\
\text { MVPA-active hours/week } \\
\text { AME }(95 \% \mathrm{Cl})^{\mathrm{a}}\end{array}$} & \multirow[t]{2}{*}{$\overline{P \text {-value }}$} \\
\hline & & & $\operatorname{AME}(95 \% \mathrm{Cl})^{\mathrm{a}}$ & & & \\
\hline \multicolumn{7}{|l|}{ Men } \\
\hline \multicolumn{7}{|l|}{ Total: } \\
\hline Middle vs lowest & $3.1(1.9,4.3)$ & $<0.001$ & $2.7(1.4,4.0)$ & $<0.001$ & $2.3(0.9,3.7)$ & 0.001 \\
\hline Highest vs lowest & $4.4(3.0,5.9)$ & $<0.001$ & $3.7(2.3,5.0)$ & $<0.001$ & $3.1(1.7,4.5)$ & $<0.001$ \\
\hline \multicolumn{7}{|l|}{ Sports/exercise: } \\
\hline Middle vs lowest & $8.0(5.1,10.8)$ & 0.002 & $0.9(0.3,1.5)$ & 0.002 & $0.5(-0.4,1.4)$ & 0.254 \\
\hline Highest vs lowest & $17.0(14.1,19.8)$ & $<0.001$ & $2.2(1.6,2.8)$ & $<0.001$ & $1.3(0.4,2.1)$ & 0.003 \\
\hline \multicolumn{7}{|l|}{ Domestic: } \\
\hline Middle vs lowest & $0.5(-2.3,3.3)$ & 0.744 & $-0.1(-0.2,0.1)$ & 0.260 & $-0.2(-0.5,0.1)$ & 0.187 \\
\hline Highest vs lowest & $4.4(1.7,7.2)$ & 0.002 & $-0.1(-0.2,0.1)$ & 0.314 & $-0.3(-0.6,0.0)$ & 0.025 \\
\hline \multicolumn{7}{|l|}{ Walking: } \\
\hline Middle vs lowest & $3.2(0.3,6.1)$ & 0.031 & $-0.3(-0.8,0.1)$ & 0.145 & $-0.9(-1.7,-0.2)$ & 0.018 \\
\hline Highest vs lowest & $13.0(10.3,15.8)$ & $<0.001$ & $0.2(-0.3,0.6)$ & 0.430 & $-0.9(-1.7,-0.2)$ & 0.015 \\
\hline \multicolumn{7}{|l|}{ Manual: } \\
\hline Middle vs lowest & $4.3(1.8,6.9)$ & 0.001 & $0.3(0.1,0.5)$ & 0.001 & $0.5(0.0,1.0)$ & 0.059 \\
\hline Highest vs lowest & $5.4(2.9,7.9)$ & $<0.001$ & $0.2(0.0,0.3)$ & 0.039 & $0.0(-0.5,0.4)$ & 0.843 \\
\hline \multicolumn{7}{|l|}{ Occupational: } \\
\hline Middle vs lowest & $6.9(4.5,9.4)$ & $<0.001$ & $1.3(0.6,2.0)$ & 0.001 & $0.1(-2.7,2.9)$ & 0.960 \\
\hline Highest vs lowest & $-1.7(-4.0,0.6)$ & 0.139 & $-1.1(-1.8,-0.4)$ & 0.001 & $-5.1(-7.9,-2.3)$ & $<0.001$ \\
\hline \multicolumn{7}{|l|}{ Women } \\
\hline \multicolumn{7}{|l|}{ Total: } \\
\hline Middle vs lowest & $1.3(0.4,2.2)$ & 0.004 & $1.1(0.0,2.2)$ & 0.041 & $1.0(-0.2,2.2)$ & 0.089 \\
\hline Highest vs lowest & $3.1(2.1,4.2)$ & $<0.001$ & $2.5(1.4,3.6)$ & $<0.001$ & $2.1(1.0,3.3)$ & $<0.001$ \\
\hline \multicolumn{7}{|l|}{ Sports/exercise: } \\
\hline Middle vs lowest & $8.3(6.0,10.7)$ & $<0.001$ & $0.6(0.2,0.9)$ & 0.001 & $0.2(-0.3,0.8)$ & 0.431 \\
\hline Highest vs lowest & $18.8(16.4,21.2)$ & $<0.001$ & $1.7(1.3,2.1)$ & $<0.001$ & $1.0(0.5,1.6)$ & $<0.001$ \\
\hline \multicolumn{7}{|l|}{ Domestic: } \\
\hline Middle vs lowest & $-1.7(-3.7,0.2)$ & 0.082 & $-0.3(-0.6,-0.1)$ & 0.017 & $-0.4(-0.7,0.0)$ & 0.045 \\
\hline Highest vs lowest & $-4.0(-6.0,-1.9)$ & $<0.001$ & $-0.7(-1.0,-0.4)$ & $<0.001$ & $-0.8(-1.1,-0.4)$ & $<0.001$ \\
\hline \multicolumn{7}{|l|}{ Walking: } \\
\hline Middle vs lowest & $2.9(0.4,5.3)$ & 0.021 & $-0.1(-0.5,0.3)$ & 0.606 & $-0.6(-1.3,0.1)$ & 0.107 \\
\hline Highest vs lowest & $10.2(7.6,12.8)$ & $<0.001$ & $0.2(-0.3,0.6)$ & 0.487 & $-1.0(-1.7,-0.2)$ & 0.012 \\
\hline \multicolumn{7}{|l|}{ Manual: } \\
\hline Middle vs lowest & $1.1(-0.7,3.0)$ & 0.220 & $0.1(0.0,0.2)$ & 0.093 & $0.3(-0.2,0.9)$ & 0.231 \\
\hline Highest vs lowest & $2.0(0.2,3.9)$ & 0.032 & $0.1(0.0,0.2)$ & 0.047 & $0.2(-0.2,0.7)$ & 0.331 \\
\hline \multicolumn{7}{|l|}{ Occupational: } \\
\hline Middle vs lowest & $2.1(0.5,3.7)$ & 0.010 & $0.6(0.2,1.0)$ & 0.001 & $3.0(0.3,5.7)$ & 0.030 \\
\hline Highest vs lowest & $-1.2(-2.9,0.4)$ & 0.132 & $-0.2(-0.6,0.1)$ & 0.201 & $-0.7(-3.5,2.1)$ & 0.620 \\
\hline
\end{tabular}

$A M E$ average marginal effect

${ }^{a}$ Adjusting for age, self-rated health, smoking status and BMI status. Missing categories as additional category. AMEs evaluated at fixed values of the confounders: for persons aged 35-44 years with very good/good health, never being a regular smoker, and having a normal-weight (BMI $18.5-24.9 \mathrm{~kg} / \mathrm{m}^{2}$ ) 


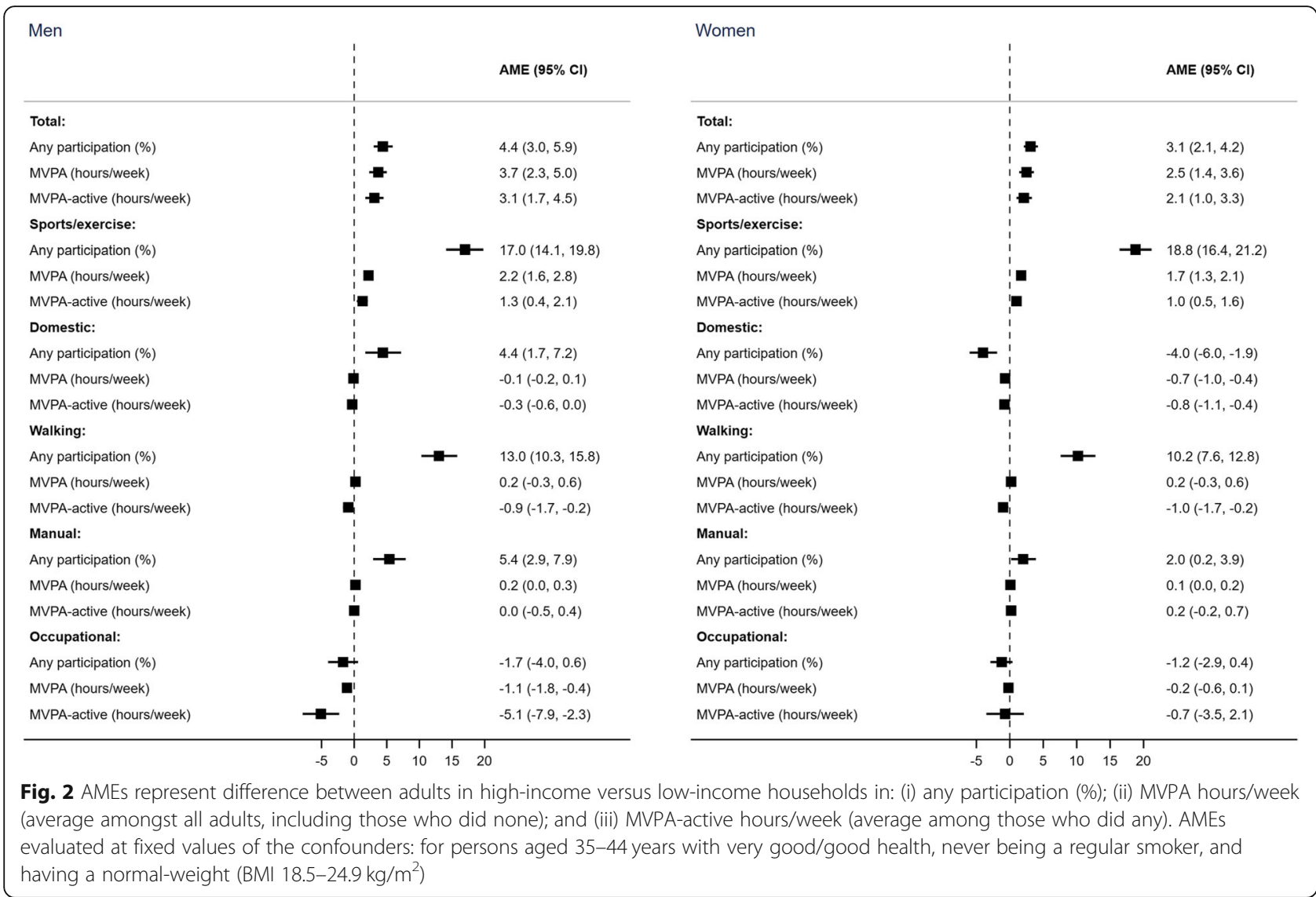

interventions to reduce the gap in activity levels rather than a "one-size-fits-all" approach [7].

\section{Implications for policy}

Differences in financial resources (especially for sports/ exercise) [5] [39], health status [40], psychological or cultural characteristics [40, 41], and the built environment $[40,42,43]$, including those driving inequalities in access to highly walkable neighbourhoods [44, 45], are key determinants of inequalities in physical activity. Reducing the inequalities presented here for sports/exercise will require policy actions and interventions to move adults in low-income households from inactivity to activity, and to enable those already active to do more. For example, removing user charges from leisure facilities in northwest England has had some success in increasing overall activity levels and in reducing inequalities [46]. Having world-class sports facilities that are free for anyone to use - as is the case in several Latin American cities - would reduce inequalities [47]. In contrast, our results suggest that interventions to promote walking should focus on reducing the sizeable income gap in the propensity to do any walking; such interventions could positively impact PA levels and reduce inequalities through increasing activity in the most sedentary [48] as well as the elderly and those in poorer health. A recent systematic review and meta-analysis [49] examined the effectiveness of interventions such as individual counselling [50], group training sessions [50, 51] and behavioural informatics [52] that were targeted at changing physical activity behaviour among low-income adults. The results showed a small positive intervention effect among those that focused on PA only as opposed to those targeting multiple behaviours [49]. However, evidence suggests that PA interventions are less effective in low-income groups, potentially widening rather than reducing inequalities [49]. Worryingly, a recent systematic review identified that there is insufficient evidence to allow for firm conclusions to be made regarding the impact of PA interventions on inequalities [53]. According to the WHO, effective national action to reduce disparities in PA requires a strategic combination of population-based policy actions aimed at tackling the "upstream" determinants that shape the equity of opportunities for participation (such as encouraging nonmotorised modes of travel through improved provision of cycling and walking infrastructure, improved road safety, and creating more opportunities for PA in public open spaces and local community settings [54]) and those policy actions that are 
focused on "downstream" individually-focused (educational and informational) interventions, implemented in ways consistent with the principle of proportional universality (i.e. greatest efforts directed towards those least active) [55].

\section{Strengths and limitations}

Our analyses used novel modelling methods to assess inequalities in MVPA. Although it is well-known that MVPA distributions typically contain excess zeros and positive skewness, no epidemiological studies to date have applied hurdle models to assess inequalities. Such models avoid the loss of information and power that occurs when practitioners typically categorise a continuous variable into a binary or ordinal variable [9]. Precision of our estimates was increased by pooling standardised PA data across survey years. Caution is required, however, when interpreting our findings. First, self-reported PA data has well-known limitations such as recall and reporting (social desirability) bias [56, 57]. Secondly, the dataset contained a sizeable amount of missing data for income and BMI ( 20\%); among HSE participants, the probability of having missing income data varies systematically across groups [58], which we minimised to some extent through applying non-response weights. The software routine for estimating hurdle models does not currently permit multiply imputed data, and so our findings may be statistically underpowered to some extent. Thirdly, the choice of potential confounders was limited to some extent by data availability; furthermore, we were unable to account for ethnic differences due to small numbers. As in all studies, our findings could have been influenced by unmeasured confounders. Fourthly, our findings are contingent upon HSE data collection, including the minimum duration of $10 \mathrm{~min}$ (in accord with the contemporaneous UK guidance but differing from recent UK [59] and US [60] guidelines, which acknowledge that PA of any duration enhances health), a specific subset of occupational PA for a selected group of occupations, and the inability to distinguish between walking for leisure and active travel. We acknowledge that different definitions may have led to different conclusions. Finally, we cannot draw causal inferences, as this was a descriptive study based on cross-sectional data.

\section{Future research}

As mentioned previously, more evidence on the equitable impact of PA interventions is needed to ascertain 'what works' best to increase PA levels among lowincome groups [49]. Given the aforementioned limitations of cross-sectional data on self-reported PA collected within large-scale national health examination surveys, it is imperative that innovative studies such as those using smartphones with built-in accelerometry to measure PA on a global scale [61] be used to shed light on inequalities and their interaction with aspects of the built environment such as walkability. However, maximising the potential for such research to inform policy-makers and practitioners will require efforts to minimise the potential bias of such data towards younger, more affluent, and more active populations [61]. Finally, as emphasised in this study, whatever the source of data, separate model equations should be used to assess inequalities in participation and in duration.

\section{Conclusion}

Monitoring inequalities in MVPA requires assessing different aspects of the distribution within each domain. In the present study, income-based inequalities were evident in the propensity to do any sports/exercise and walking, and for the amount of time spent doing sports/ exercise. These findings may assist policy-makers to identify and commission tailored interventions best suited to tackling inequalities, and our methods could be used by practitioners to evaluate their impact.

\section{Supplementary information}

Supplementary information accompanies this paper at https://doi.org/10. 1186/s12889-020-08479-x.

Additional file 1: Distribution of participants on the key variables by income tertile and gender, Health Survey for England 2008, 2012 and 2016.

\section{Abbreviations}

AME: Average marginal effects; BMl: Body mass index; HSE: Health Survey for England; MVPA: Moderate-to-vigorous physical activity; PA: Physical activity; PASBAQ: Physical activity and sedentary behaviour assessment questionnaire; SEP: Socio-economic position; WHO: World Health Organization

\section{Acknowledgements \\ The authors thank the interviewers and the nurses, and the participants in the Health Survey for England series.}

\section{Authors contributions}

SS conceptualized the study. SS was responsible for conducting the analyses, interpreting the results and drafting the manuscript. SS and JSM critically revised the manuscript. Both authors have read and approved the final manuscript.

\section{Funding}

The Health Survey for England (HSE) was funded by NHS Digital. NHS Digital is the trading name of the Health and Social Care Information Centre. The authors are funded to conduct the annual HSE but this specific study was not funded. NHS Digital had no role in the analysis, interpretation of data, decision to publish or preparation of the manuscript for this specific study.

\section{Availability of data and materials}

The HSE datasets generated and/or analysed during the current study are available via the UK Data Service (UKDS: https://ukdataservice.ac.uk/). Syntax to enable replication of our results (using the datasets deposited at the UKDS) is available on request from the corresponding author. 


\section{Ethics approval and consent to participate}

Each sampled address for the HSE is sent an advance letter which introduces the survey and states that an interviewer would be calling to seek permission to interview. A leaflet is also enclosed providing general information about the survey and some of the findings from previous surveys. Individual interviews are conducted with adults who give verbal informed consent. At the end of individual interviews, participants are asked for agreement to a follow-up visit by a trained nurse. Written consent is obtained for collection of non-fasting blood samples. It is made clear in the advance letters and information leaflets that participation in the survey is entirely voluntary, and that participants may decline to answer individual questions, withdraw or stop at any time, or refuse any particular measurement if they wish to do so. Interviewers and nurses will often repeat this information in their introductions and when they are setting up appointments, and throughout the interview as necessary. Indeed, many individuals do refuse to participate in the survey; others may refuse individual questions, decline to continue part way through an interview or refuse physical measurements. It is also standard practice to conduct interviews and nurse visits some time after an appointment has been made so that individuals have a chance to reflect on their agreement before the appointment takes place. The procedures used in the HSE to obtain informed consent are very closely scrutinised by a National Health Service (NHS) ethics committee each year. Information leaflets and both the content and wording of questionnaires are also carefully reviewed by the ethics committees. Research ethics approval for the HSE 2008 and HSE 2012 was obtained from the Oxford A Research Ethics Committee (reference number 07/H0604/102 and 10/H0604/ 56, respectively); ethical approval for the HSE 2016 was obtained from the East Midlands Nottingham 2 Research Ethics Committee (Reference no 15/ EM/0254).

\section{Consent for publication}

Not applicable.

\section{Competing interests}

The authors declare that they have no competing interests.

\section{Received: 23 January 2020 Accepted: 6 March 2020}

Published online: 19 March 2020

\section{References}

1. Lear SA, Hu W, Rangarajan S, Gasevic D, Leong D, lqbal R, et al. The effect of physical activity on mortality and cardiovascular disease in 130000 people from 17 high-income, middle-income, and low-income countries: the PURE study. Lancet. 2017;390:2643-54.

2. Stringhini S, Sabia S, Shipley M, Brunner E, Nabi H, Kivimaki M, et al, Association of socioeconomic position with health behaviors and mortality. JAMA. 2010:303:1159-66.

3. Laine JE, Baltar VT, Stringini S, Gandini M, Chadeau-Hyam M, Kivimaki M, et al. Reducing socio-economic inequalities in all-cause mortality: a counterfactual mediation approach. Int J Epidemiol. 2019. https://doi.org/10. 1093/ije/dyz248.

4. Scholes S, Bann D. Education-related disparities in reported physical activity during leisure-time, active transportation, and work among US adults: repeated cross-sectional analysis from the National Health and nutrition examination surveys, 2007 to 2016. BMC Public Health. 2018;18:926.

5. Beenackers MA, Kamphuis CBM, Giskes K, Brug J, Kunst AE, Burdorf A, et al. Socioeconomic inequalities in occupational, leisure-time, and transport related physical activity among European adults: a systematic review. Int J Behav Nutr Phys Act. 2012;9:116.

6. Du Y, Liu B, Sun Y, Snetselaar LG, Wallace RB, Bao W. Trends in adherence to the physical activity guidelines for Americans for aerobic activity and time spent on sedentary behavior among US adults, 2007 to 2016. JAMA Netw Open. 2019;2:e197597.

7. Hunter RF, Boeri M, Tully MA, Donnelly P, Kee F. Addressing inequalities in physical activity participation: implications for public health policy and practice. Prev Med. 2015;72:64-9.

8. Roberts D, Townsend N, Foster C. Use of new guidance to profile 'equivalent minutes' of aerobic physical activity for adults in England reveals gender, geographical, and socio-economic inequalities in meeting public health guidance: a cross-sectional study. Prev Med Rep. 2016;4:50-60.
9. Royston P, Ambler G, Sauerbrei W. The use of fractional polynomials to model continuous risk variables in epidemiology. Int J Epidemiol. 1999;28:964-74.

10. Davillas A, Jones AM, Benzeval M. The income-health gradient: Evidence from self-reported health and biomarkers using longitudinal data on income. ISER Working Paper Series, No. 2017-03. Colchester: University of Essex, Institute for Social and Economic Research (ISER); 2017.

11. Rodriguez-Caro A, Vallejo-Torres L, Lopez-Valcarcel B. Unconditional quantile regressions to determine the social gradient of obesity in Spain 1993-2014. Int J Equity Health. 2016;15:175.

12. Gebremariam MK, Arah OA, Lien N, Naess O, Ariansen I, Kjollesdal MK. Change in BMI Distribution over a 24-Year Period and Associated Socioeconomic Gradients: A Quantile Regression Analysis. Obesity (Silver Spring). 2018;26:769-75.

13. Baldwin SA, Fellingham GW, Baldwin AS. Statistical models for multilevel skewed physical activity data in health research and behavioral medicine. Health Psychol. 2016;35:552-62.

14. Humphreys BR, Ruseski JE. The economic choice of participation and time spent in physical activity and sport in Canada. Int J Sport Financ. 2015;10:138-59.

15. Cragg JG. Some statistical models for limited dependent variables with application to the demand for durable goods. Econometrica. 1971;39:829-44.

16. Buraimo B, Humphreys B, Simmons R. Participation and engagement in sport: a double hurdle approach for the United Kingdom. The Selected Works of Dr Babatunde Buraimo. United Kingdom: University of Central Lancashire; 2010.

17. Scholes S, Mindell J. Health Survey for England 2012 - Chapter 2: Physical Activity in Adults. Leeds: Health and Social Care Information Centre; 2013.

18. Scholes S, Neave A. Health Survey for England 2016 - Physical activity in Adults. Leeds: Health and Social Care Information Centre; 2017.

19. Mindell J, Biddulph JP, Hirani V, Stamatakis E, Craig R, Nunn S, et al. Cohort profile: the health survey for England. Int J Epidemiol. 2012;41:1585-93.

20. Stamatakis E, Lee I-M, Bennie J, Freeston J, Hamer M, O'Donovan G, et al. Does strength-promoting exercise confer unique health benefits? A pooled analysis of data on 11 population cohorts with all-cause, cancer, and cardiovascular mortality endpoints. Am J Epidemiol. 2017;187:1102-12.

21. Hamer M, O'Donovan G, Stamatakis E. Association between physical activity and sub-types of cardiovascular disease death causes in a general population cohort. Eur J Epidemiol. 2019;34:483-7.

22. Scholes S, Coombs N, Pedisic Z, Mindell JS, Bauman A, Rowlands AV, et al. Age-and sex-specific criterion validity of the health survey for England physical activity and sedentary behavior assessment questionnaire as compared with accelerometry. Am J Epidemiol. 2014;179:1493-502.

23. Scholes S, Bridges S, Fat LN, Mindell JS. Comparison of the physical activity and sedentary behaviour assessment questionnaire and the short-form international physical activity questionnaire: an analysis of health survey for England data. PLoS One. 2016;11:e0151647.

24. Ainsworth BE, Haskell WL, Whitt MC, Irwin ML, Swartz AM, Strath SJ, et al. Compendium of physical activities: an update of activity codes and MET intensities. Med Sci Sports Exerc. 2000;32(9; SUPP/1):S498-504.

25. Ainsworth BE, Haskell WL, Herrmann SD, Meckes N, Bassett DRJ, TudorLocke C, et al. 2011 compendium of physical activities: a second update of codes and MET values. Med Sci Sports Exerc. 2011:43:1575-81.

26. Chief Medical Officers. Start Active, Stay Active: A report on physical activity from the four home countries'. A Report on Physical Activity from the four Home Countries. London: The Department of Health; 2011.

27. Mcclements LD. Equivalence scales for children. J Public Econ. 1977;8:191-210.

28. World Health Organization. BMI Classification. 2006. Available at http://www. assessmentpsychology.com/icbmi.htm. Accessed 1/3 2020.

29. Rao JNK, Scott AJ. The analysis of categorical data from complex sample surveys: chi-squared tests for goodness of fit and independence in two-way tables. J Am Stat Assoc. 1981;76:221-30.

30. Demarest S, Van Oyen H, Roskam A-J, Cox B, Regidor E, Mackenbach JP, et al. Educational inequalities in leisure-time physical activity in 15 European countries. Eur J Pub Health. 2013;24:199-204.

31. Heeringa SG, West BT, Berglund PA. Applied Survey Data Analysis. Boca Raton: Chapman and Hall/CRC press; 2017.

32. Eakins J. An application of the double hurdle model to petrol and diesel household expenditures in Ireland. Transp Policy. 2016;47:84-93.

33. National Centre for Social Research, University College London, Department of Epidemiology and Public Health. Health Survey for England, 2008. [data collection]. $4^{\text {th }}$ Edition. UK Data Service. SN: 6397, 2013. https://doi.org/10. 5255/UKDA-SN-6397-2 
34. NatCen Social Research, University College London, Department of Epidemiology and Public Health. Health Survey for England, 2012. [data collection]. UK Data Service. SN: 7480, 2014. https://doi.org/10.5255/UKDA-SN-7480-1.

35. NatCen Social Research, University College London, Department of Epidemiology and Public Health. Health Survey for England, 2016. [data collection]. $3^{\text {rd }}$ Edition. UK Data Service. SN: 8334, 2019. https://doi.org/10. 5255/UKDA-SN-8334-3.

36. Gerovasili V, Agaku IT, Vardavas Cl, Filippidis FT. Levels of physical activity among adults 18-64 years old in 28 European countries. Prev Med. 2015;81:87-91.

37. Holtermann A, Krause N, Van Der Beek AJ, Straker L. The physical activity paradox: six reasons why occupational physical activity (OPA) does not confer the cardiovascular health benefits that leisure time physical activity does. 2018. Br J Sports Med. 2018:52:149-50.

38. White RL, Babic MJ, Parker PD, Lubans DR, Astell-Burt T, Lonsdale C. Domain-specific physical activity and mental health: a meta-analysis. Am J Prev Med. 2017:52:653-66.

39. Gidlow $C$, Johnston $L H$, Crone D, Ellis $N$, James D. A systematic review of the relationship between socio-economic position and physical activity. Health Educ J. 2006;65:338-67.

40. Bauman AE, Reis RS, Sallis JF, Wells JC, Loos RJF, Martin BW, et al. Correlates of physical activity: why are some people physically active and others not? Lancet. 2012;380:258-71.

41. Bauman A, Ma G, Cuevas F, Omar Z, Waqanivalu T, Phongsavan P, et al. Cross-national comparisons of socioeconomic differences in the prevalence of leisure-time and occupational physical activity, and active commuting in six Asia-Pacific countries. J Epidemiol Community Heal. 2011;65:35-43.

42. Sallis JF, Cerin E, Conway TL, Adams MA, Frank LD, Pratt M, et al. Physical activity in relation to urban environments in 14 cities worldwide: a crosssectional study. Lancet. 2016;387:2207-17.

43. Owen N, Leslie E, Salmon J, Fotheringham MJ. Environmental determinants of physical activity and sedentary behavior. Exerc Sport Sci Rev. 2000;28:153-8.

44. Sugiyama T, Cole R, Koohsari MJ, Kynn M, Sallis JF, Owen N. Associations of local-area walkability with disparities in residents' walking and car use. Prev Med. 2019;120:126-30.

45. Weng M, Ding N, Li J, Jin X, Xiao H, He Z, et al. The 15-minute walkable neighborhoods: measurement, social inequalities and implications for building healthy communities in urban China. J Transp Heal. 2019;13:259-73.

46. Higgerson J, Halliday E, Ortiz-Nunez A, Brown R, Barr B. Impact of free access to leisure facilities and community outreach on inequalities in physical activity: a quasi-experimental study. J Epidemiol Community Heal. 2018;72:252-8.

47. O'Donovan G. Accuracy and inequalities in physical activity research. Lancet Glob Health. 2019;7(2):e186

48. Ogilvie D, Foster CE, Rothnie H, Cavill N, Hamilton V, Fitzsimons CF, et al. Interventions to promote walking: systematic review. BMJ. 2007;334:1204.

49. Bull ER, Dombrowski SU, McCleary N, Johnston M. Are interventions for lowincome groups effective in changing healthy eating, physical activity and smoking behaviours? A systematic review and meta-analysis. BMJ Open. 2014; $4:$ e006046

50. Keyserling TC, Hodge CDS, Jilcott SB, Johnston LF, Garcia BA, Gizlice Z, et al. Randomized trial of a clinic-based, community-supported, lifestyle intervention to improve physical activity and diet: the North Carolina enhanced WISEWOMAN project. Prev Med. 2008:46:499-510.

51. Dangour AD, Albala C, Allen E, Grundy E, Walker DG, Aedo C, et al. Effect of a nutrition supplement and physical activity program on pneumonia and walking capacity in Chilean older people: a factorial cluster randomized trial. PLoS Med. 2011:8(4):e1001023.

52. Pekmezi DW, Neighbors CJ, Lee CS, Gans KM, Bock BC, Morrow KM, et al. A culturally adapted physical activity intervention for Latinas: a randomized controlled trial. Am J Prev Med. 2009;37:495-500.

53. Lehne $\mathrm{G}$, Bolte $\mathrm{G}$. Impact of universal interventions on social inequalities in physical activity among older adults: an equity-focused systematic review. Int J Behav Nutr Phys Act. 2017;14:20.

54. Guthold R, Stevens GA, Riley LM, Bull FC. Global trends in insufficient physical activity among adolescents: a pooled analysis of 298 populationbased surveys with 1.6 million participants. Lancet Child Adolesc Heal. 2020:4:23-35.

55. World Health Organization. Global action plan on physical activity 2018-2030: more active people for a healthier world. Geneva: World Health Organization; 2019.
56. Adams SA, Matthews CE, Ebbeling CB, Moore CG, Cunningham JE, Fulton J, et al. The effect of social desirability and social approval on self-reports of physical activity. Am J Epidemiol. 2005;161:389-98.

57. Ferrari $P$, Friedenreich $C$, Matthews CE. The role of measurement error in estimating levels of physical activity. Am J Epidemiol. 2007;166:832-40.

58. Scholes S, Conolly A, Mindell J. Income-based inequalities in hypertension and in undiagnosed hypertension: analysis of health survey for England data. J Hypertens. 2020. https://doi.org/10.1097/HJH.0000000000002350.

59. Department of Health and Social Care, Llwodraeth Cymru Welsh Government, Department of Health Northern Ireland and the Scottish Government. UK Chief Medical Officers' Physical Activity Guidelines. London: Department of Health and Social Care; 2019.

60. Piercy KL, Troiano RP, Ballard RM, Carlson SA, Fulton JE, Galuska DA, et al. The physical activity guidelines for Americans. JAMA. 2018;320:2020-8.

61. Althoff T, Hicks JL, King AC, Delp SL, Leskovec J. Large-scale physical activity data reveal worldwide activity inequality. Nature. 2017;547:336.

\section{Publisher's Note}

Springer Nature remains neutral with regard to jurisdictional claims in published maps and institutional affiliations.

\section{Ready to submit your research? Choose BMC and benefit from:}

- fast, convenient online submission

- thorough peer review by experienced researchers in your field

- rapid publication on acceptance

- support for research data, including large and complex data types

- gold Open Access which fosters wider collaboration and increased citations

- maximum visibility for your research: over $100 \mathrm{M}$ website views per year

At BMC, research is always in progress.

Learn more biomedcentral.com/submissions 